\title{
Occupation- and age-associated risk of SARS-CoV-2 test positivity, the Netherlands, June to October 2020
}

Brechje de Gier ${ }^{1}$, Priscila de Oliveira Bressane Lima ${ }^{1}$, Rolina D van Gaalen ${ }^{1}$, Pieter T de Boer ${ }^{1}$, Jeroen Alblas ${ }^{1}$, Marc Ruijten², Arianne B van Gageldonk-Lafeber ${ }^{1}$, Toos Waegemaekers ${ }^{1,3}$, Anja Schreijer ${ }^{4}$, Susan van den Hof ${ }^{1}$, Susan JM Hahné ${ }^{1}$

1. Centre for Infectious Disease Control, National Institute for Public Health and the Environment (RIVM), Bilthoven, the Netherlands

2. GGDGHOR Nederland, Utrecht, the Netherlands

3. Public Health Service Gelderland Midden, Arnhem, the Netherlands

4. National Consultation on Infectious Disease Control (LOI), Public Health Service (GGD) Amsterdam, the Netherlands

Correspondence: Brechje de Gier (Brechje.de.gier@rivm.nl)

de Gier Brechje, de Oliveira Bressane Lima1 Priscila, van Gaalen Rolina D, de Boer Pieter T, Alblas Jeroen, Ruijten Marc, van Gageldonk-Lafeber Arianne B,

Waegemaekers Toos, Schreijer Anja, van den Hof Susan, Hahné Susan JM. Occupation-and age-associated risk of SARS-CoV-2 test positivity, the Netherlands, June to October 2020. Euro Surveill. 2020;25(50):pii=2001884. https://doi.org/10.2807/1560-7917.ES.2020.25.50.2001884

High coronavirus incidence has prompted the Netherlands to implement a second lockdown. To elucidate the epidemic's development preceding this second wave, we analysed weekly test positivity in public test locations by population subgroup between 1 June and 17 October 2020. Hospitality and public transport workers, driving instructors, hairdressers and aestheticians had higher test positivity compared with a reference group of individuals without a close-contact occupation. Workers in childcare, education and healthcare showed lower test positivity.

An understanding of the main factors contributing to community transmission of coronavirus disease (COVID-19) is urgently needed to inform targeted prevention policies so that further transmission can be controlled while minimising effects on society and the economy. Here we present test positivity by age group (for individuals $<25$ years old) or by occupational group ( $\geq 25$ years old), per week, from June to October 2020 in the Netherlands.

\section{Epidemiological situation and mass testing}

The first case of COVID-19 in the Netherlands was diagnosed on 27 February 2020, after which incidence increased rapidly, peaking at 20 new COVID-19 hospitalisations per 100,000 population in week 13 (22-28 March). A nationwide lockdown was implemented on 12 March, resulting in a rapid decline in the number of COVID-19-related hospitalisations (Figure 1). The number of hospitalisations plateaued after week 23 (1 June), with 0.5 weekly hospitalisations per 100,000 population. Lockdown measures were gradually phased out in mid-May; however, the incidence of laboratory-confirmed COVID-19 hospitalisations started to slowly increase again over the course of summer. As at week 42 (mid-October), weekly hospitalisations had increased to 10 per 100,000 population.

Since 1 June 2020, the Netherlands has made severe acute respiratory syndrome coronavirus 2 (SARSCoV-2) PCR testing available for anyone experiencing symptoms compatible with COVID-19 (fever, cough, sore throat, shortness of breath, myalgia, runny nose, sudden loss of smell or taste), as well as for source and contact tracing. Individuals can apply for a test through a national call centre or, since 12 August, via an online portal. The 25 regional Public Health Services (PHS) perform sampling in public test locations. Demographic data, dates of testing and laboratory results are entered into a dedicated IT system named CoronIT. Test results are exported from CoronIT into the HPzone software at the PHS, wherein source and contact tracing data are registered. The National Institute for Public Health and the Environment (RIVM) accesses the anonymised data in CoronIT for surveillance purposes.

When requesting a test, either online or through the call centre, individuals are asked about their occupation. The question is posed as: "Have you worked in the past two weeks in the capacity of:", followed by a list of employment categories potentially associated with SARS-CoV-2 infection risk (Table 1 ). If a patient reports having recently worked in healthcare or in a closecontact profession, i.e. a profession requiring contact with other persons within $1.5 \mathrm{~m}$, a follow-up question is triggered that asks the respondent to select a specific healthcare or close-contact profession.

Using the numbers of negative and positive tests, binomial proportions of positive tests and accompanying $95 \%$ confidence intervals $(\mathrm{Cls})$ were estimated by week of sampling and stratified by occupational 


\section{FIGURE 1}

Weekly number of new COVID-19 hospitalisations and ICU admissions ${ }^{\text {a }}$, the Netherlands, March-October 2020

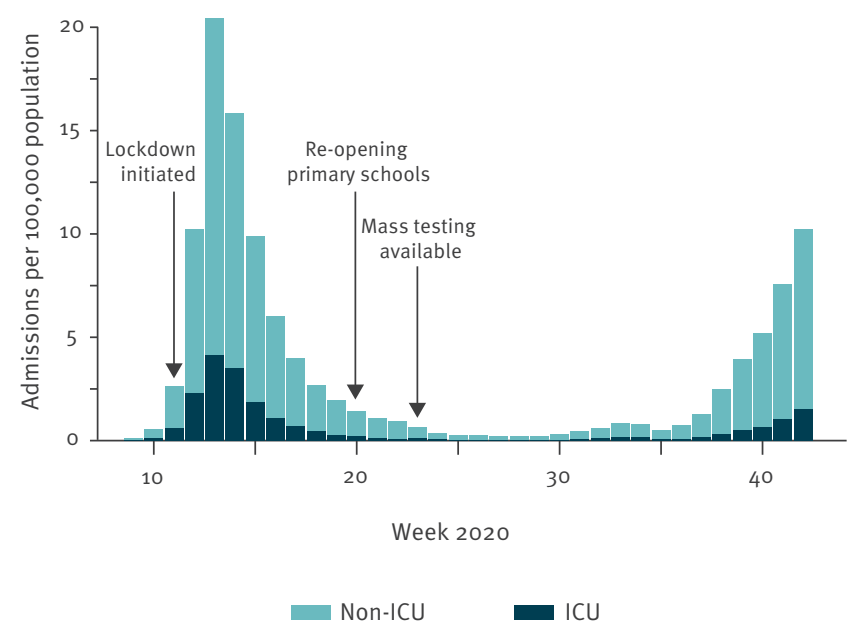

COVID-19: coronavirus disease; ICU: intensive care unit; NICE: National Intensive Care Evaluation.

a As registered by Stichting NICE [10].

category or age group for persons $\leq 24$ years of age, in $R$ 3.6.0 (prop.test, package 'stats') [1]. Individuals $\geq 25$ years that reported working in a non-close-contact occupation were used as a reference group. Healthcare workers (HCWs) were stratified by the setting in which they work (hospital, long-term care facility, elsewhere). Tests registered as performed in the context of source and contact tracing were excluded from all analyses. Total number of tests and number positive per category can be found in Supplementary Table S1. We defined relevant differences as non-overlapping 95\% Cls between the weekly test positivity of the occupational category or age group vs the reference group.

Figure 2 and Figure 3 show an overall increase in test positivity from 2 August (weeks 32-33), after which it dropped (weeks 34-35), and then steadily increased until the last week included in this analysis (week 42). The following occupational groups had generally higher test positivity than the reference group: people working in the hospitality and public transport sectors, driving instructors, hairdressers and aestheticians, although the differences in test positivity were not as pronounced in every week. Of note, the use of non-medical face masks has been obligatory in public transportation and advised for close-contact professions since 1 June; driving instructors were not advised to wear face masks until 19 October (week 43).

Figure 2 and Figure 3 also show that during the second increase in test positivity, starting at week 36, educational personnel and HCWs showed lower testpositive percentages than the reference group. These results may indicate that these occupational groups complied with the precautionary measures, including proper personal protective equipment use among
HCWs, where indicated. These results may also-at least in part-be caused by a higher testing rate among these professional categories, who-in generalcannot work from home.

Up to week 39, children < 12 years of age showed consistently lower test positivity percentages than adults. Young children are more likely to develop mild or no symptoms after SARS-CoV-2 infection [2]. Our data showed that among young children with symptoms (including mild symptoms), the SARS-CoV-2 test positivity was also lower. Since week 39 , children $<13$ years of age who had mild symptoms and no known contact with a laboratory-confirmed COVID-19 case were no longer advised to undergo SARS-CoV-2 testing because of limited testing capacity. Therefore, there was a reduction in testing among children in the age groups $0-3$ years and 4-11 years (Figure 1 ), while this change in testing policy likely increased test positivity in these age groups. The lower test positivity among educational personnel compared with the reference group was in line with the lower test positivity among primary school students (up to week 39), supporting the hypothesis that transmission of SARS-CoV-2 by primary school children is likely modest, as has been described before [3]. Preventive measures have been installed in schools, such as physical distancing between teachers and students, and secondary school students have used non-medical face masks between classes since week 42 (Table 2).

\section{Discussion and conclusions}

Evidence on occupational risk of testing positive for COVID-19 is thus far scarce. Our study's finding of increased test positivity among workers in the hospitality and public transport sectors, driving instructors, hairdressers and aestheticians not only has implications for these professionals, but also for everyone who is using these services. The registration of occupation is therefore relevant for public health policymaking. Such data are useful to evaluate COVID-19 mitigation policies and identify sectors that may be eligible for more lenient restrictions or that may require stricter restrictions. Changes to testing practices in the near future, such as rapid antigen testing, should be embedded in this surveillance so that subgroup-specific surveillance of test positivity remains possible.

The data presented in this rapid communication have several limitations. Registration of profession was incomplete; in total, profession was 'unknown' for $36 \%$ $(966,025 / 2,700,563)$ of tests (Supplementary Table S1). Completeness of information, however, improved over time: in week 23 , the occupational category was unknown for $63 \%(30,375 / 47,803)$ of tests, vs $32 \%$ $(88,771 / 276,362)$ of tests in week 41 . The category 'unknown' includes individuals who did not work in the 2 weeks preceding their test-e.g. because of (fulltime) education, unemployment, illness, vacation or retirement-and is therefore not solely 'missing data'. Also, certain occupations with a high SARS-CoV-2 
TABLE 1

Occupational categories and subcategories registered in CoronIT, occupation- and age-associated risk of SARS-CoV-2 test positivity study, the Netherlands, 2020

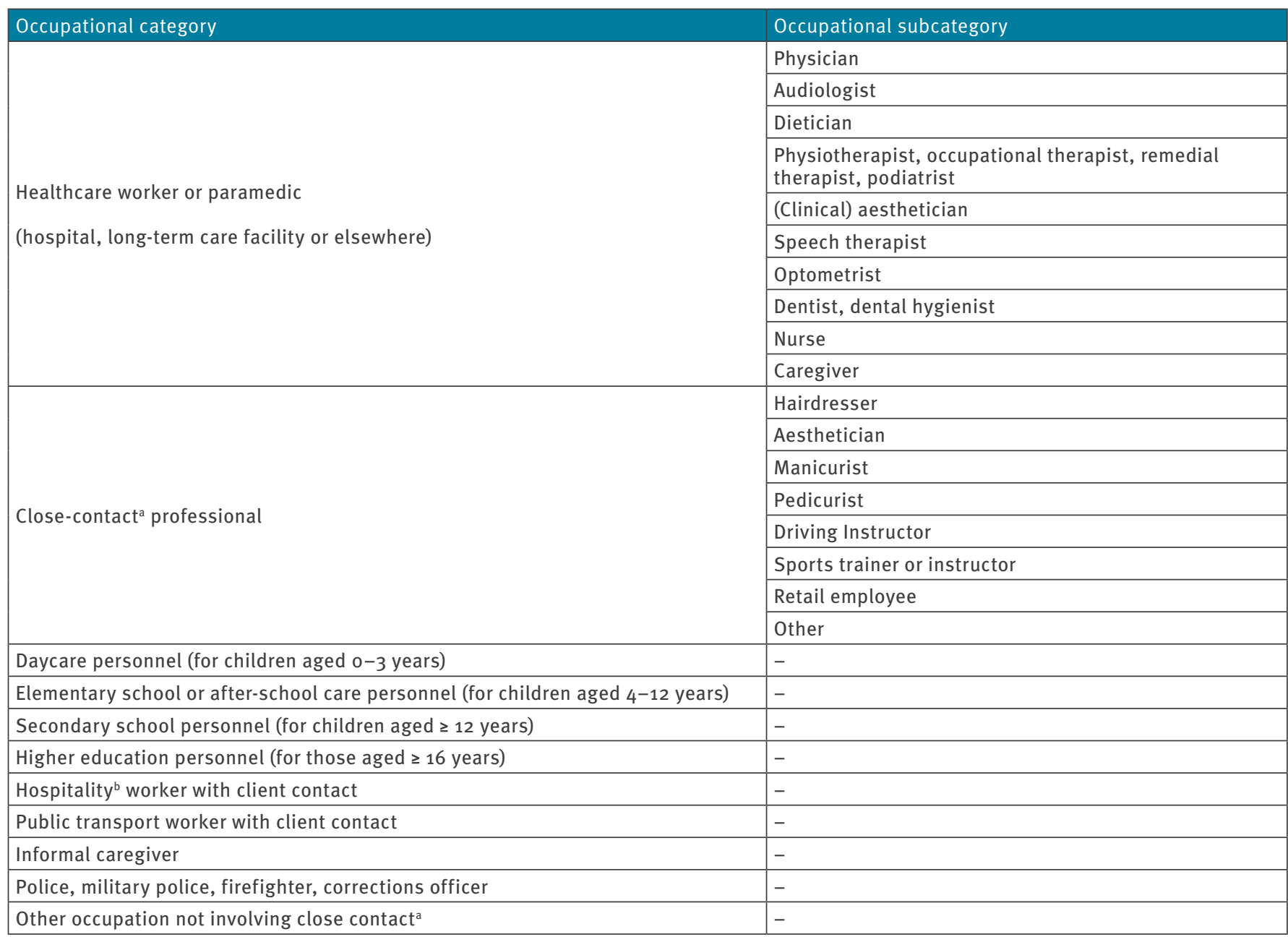

SARS-CoV-2: severe acute respiratory syndrome coronavirus 2.

a Defined as requiring contact with other persons within $1.5 \mathrm{~m}$.

${ }^{b}$ Defined as hotels, restaurants, cafes and bars.

In the Netherlands, 25 regional Public Health Services perform sampling in public test locations. Demographic data, dates of testing and laboratory results are entered into a dedicated IT system, named CoronIT.

infection risk, such as food processing [4], could not be identified in our dataset, given the limited number of occupational categories in the questionnaire.

Test positivity might not translate to COVID-19 incidences equally for all subgroups. Important unknowns are the incidence of testing by group, the incidence of COVID-19-like symptoms by group and the testing behaviour by group. The number of tests per 100,000 population, by age group, can be determined based on demographic data. Denominators for the different specific occupational groups are much more uncertain. Furthermore, since patients are categorised in an occupational group in CoronlT only if they have reported active work in the 2 weeks before their testand because this question regarding occupation is not always filled in-the numbers cannot simply be divided by denominators of known occupational group sizes. Test behaviour is also likely to differ between occupational groups, e.g. because of differences in risk perception and the extent to which it is possible to work from home. For example, for small business owners in the hospitality sector, the threshold for testing may be relatively high. In October, there were some weeks of test scarcity, during which people may have been discouraged from testing due to long delays between applying for a test and receiving results (9o hours on average in week 41), during which time patients were asked to self-isolate. As of 21 September (week 39), essential HCWs and educational personnel received priority testing to facilitate their swift return to work; since this date, the number of tested individuals among HCWs and educational personnel (especially those working in secondary education) increased and the curves for HCWs (in hospital and elsewhere) and educational personnel (secondary and higher) diverged more from the reference group.

The incidence of symptoms in different groups is even more uncertain. A novel population-based syndromic 


\section{FIGURE 2}

Number and percentages of SARS-CoV-2 PCR-positive (A) children and young adults and (B) childcare and educational personnel, the Netherlands, week 23-42 2020

\section{A. Children and young adults}

Aged o-3 years ${ }^{\mathrm{a}}$

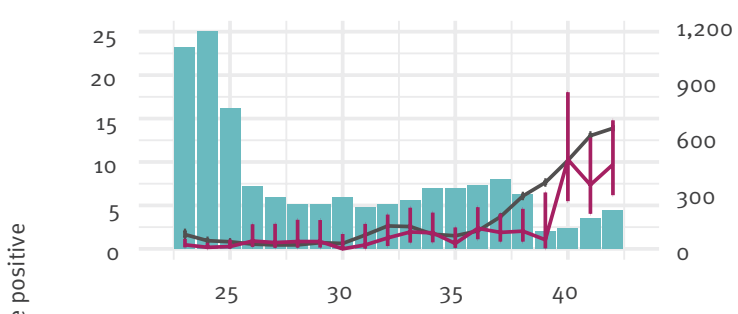

Aged 12-17 years ${ }^{\mathrm{a}}$

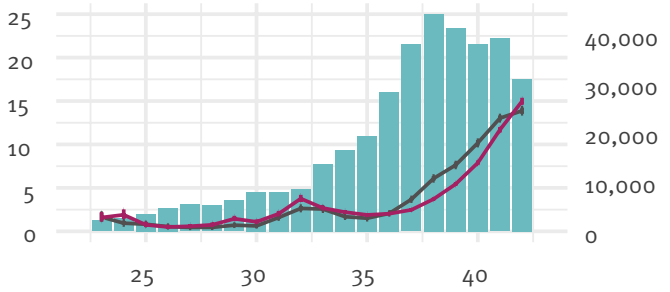

Week

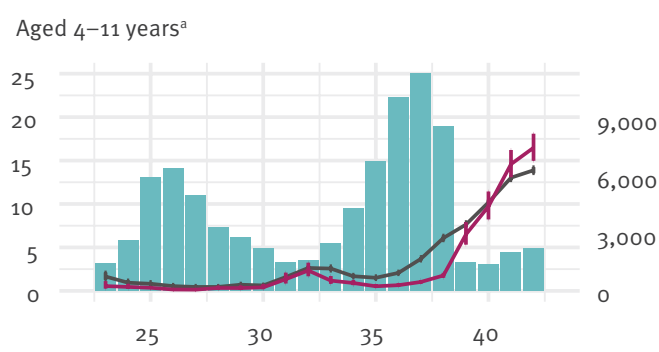

Aged 18-24 years

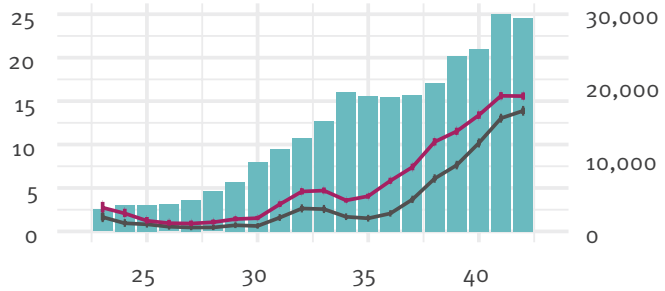

\section{B. Childcare and educational personnel}

\section{Childcare (ages 0 -3 years)}

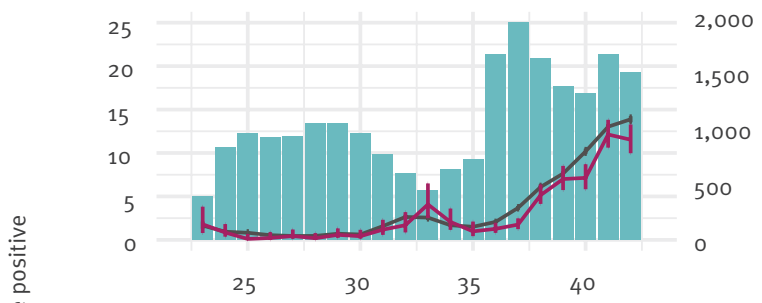

Secondary education (ages $>12$ years )

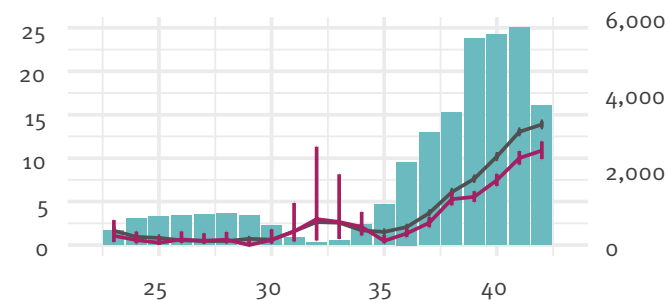

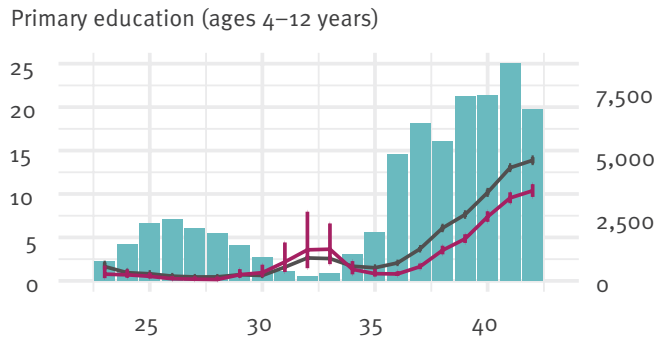

Higher education (ages > 16 years)

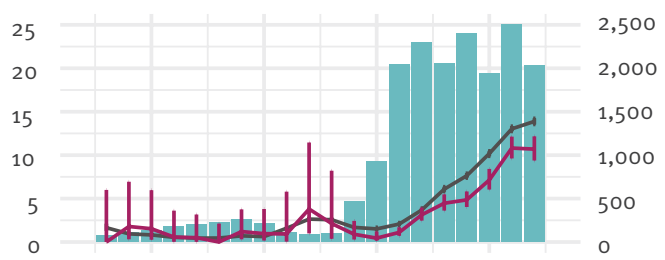

25

$\mathrm{Cl}$ : confidence interval; SARS-CoV-2: severe acute respiratory syndrome coronavirus 2.

a From week 39 onward, children $\leq 12$ years old with COVID-19 symptoms were no longer tested. Exceptions were severely ill children, symptomatic children who were a confirmed case contact or children who were part of an outbreak investigation.

Please note the different scales of the right-hand y axes. $95 \% \mathrm{Cls}$ are given as vertical error bars. Childcare and educational personnel subgroups reported working in these professions in the 2 weeks before testing. The black reference line in each subplot is the test positivity of adults that reported working in a non-close-contact profession in the 2 weeks before testing. 


\section{FIGURE 3}

Number and percentages of SARS-CoV-2 PCR-positive (A) healthcare workers, (B) close-contact professionals and (C) other professionals, the Netherlands, week 23-42 2020

\section{A. Healthcare workers}
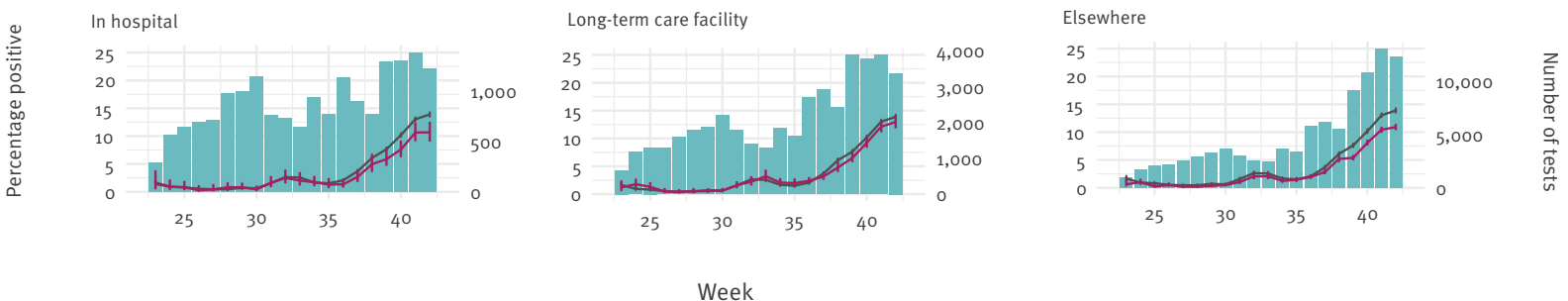

\section{B. Close-contact professions}
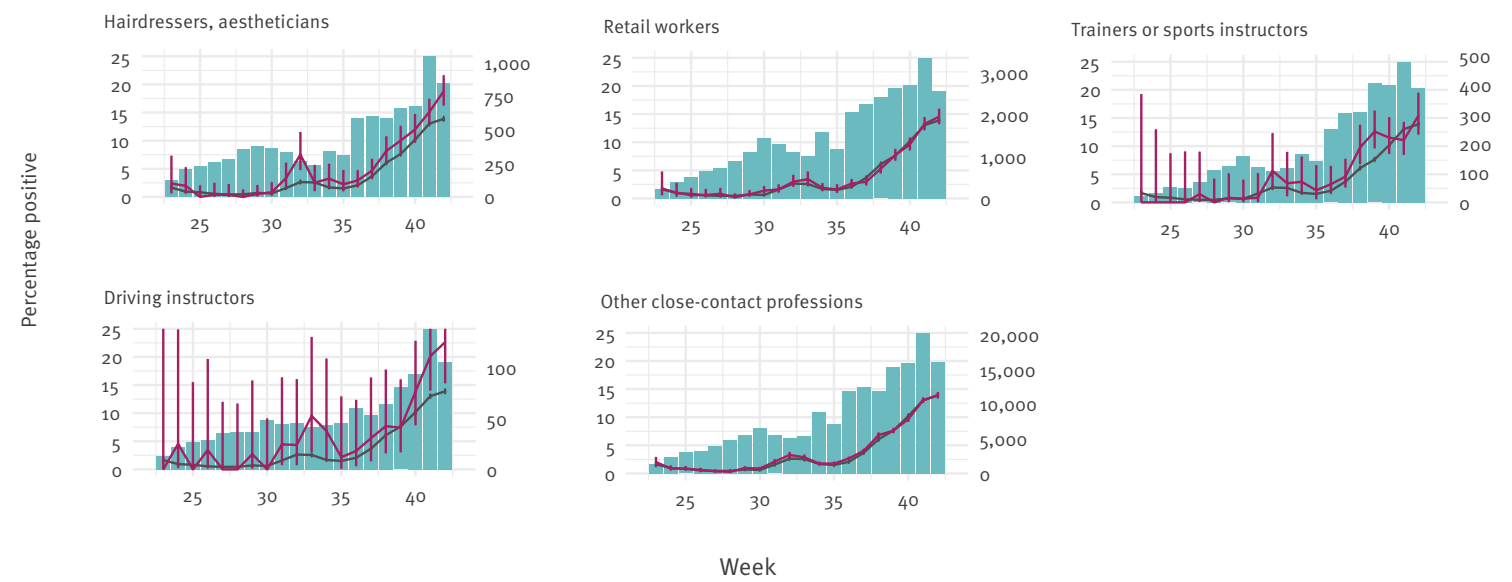

\section{Other professions}
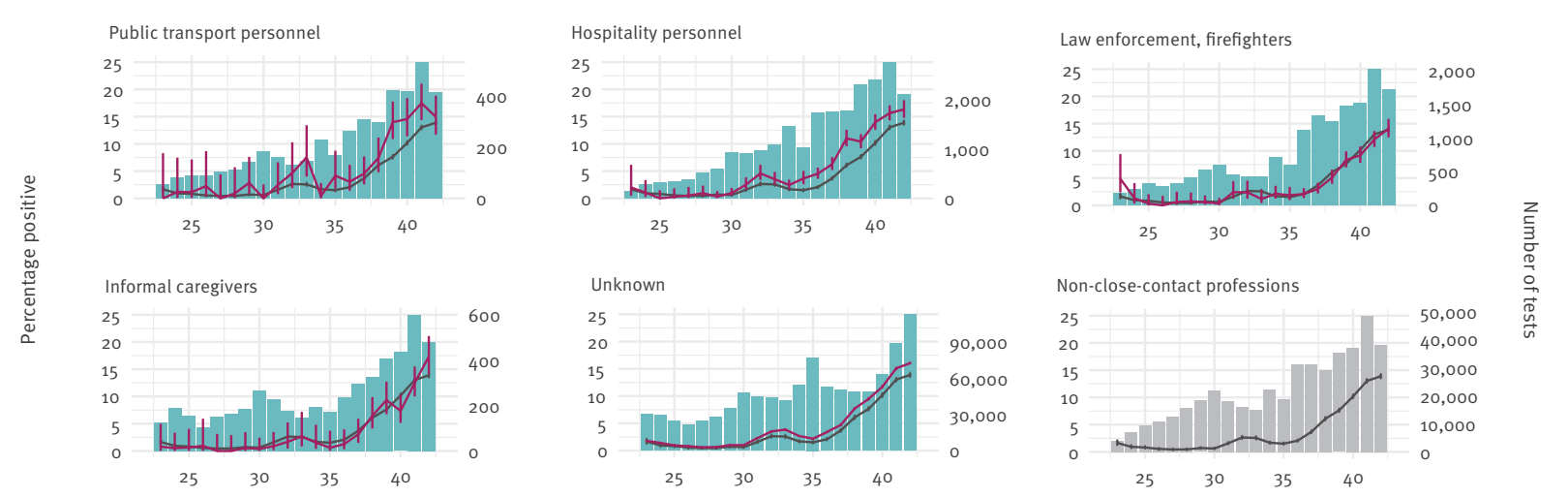

Week
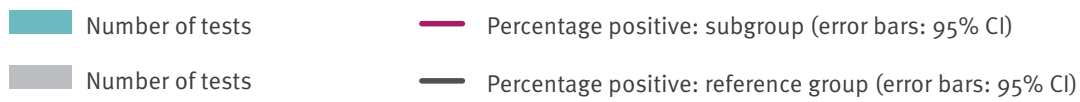

$\mathrm{CI}$ : confidence interval; SARS-CoV-2: severe acute respiratory syndrome coronavirus 2.

Please note the different scales of the right-hand y axes. $95 \% \mathrm{Cls}$ are given as vertical error bars. Occupational subgroups reported working in these professions in the 2 weeks before testing. The black reference line in each subplot is the test positivity of adults that reported working in a non-close-contact profession in the 2 weeks before testing. Weekly numbers of tests for this reference group are shown in the last plot (grey bars). 
TABLE 2

Selected COVID-19 prevention measures and testing policies, the Netherlands, 1 June-17 October 2020

\begin{tabular}{|c|c|c|}
\hline Week & Prevention measures & Testing policies \\
\hline 23 & $\begin{array}{l}\text { Maintain physical distance of } 1.5 \mathrm{~m} \text { ( }>12 \text { years old) } \\
\text { Non-medical face masks obligatory on public transport ( }>12 \text { years old) } \\
\text { Cinemas, restaurants, cafes and cultural institutions (such as concert halls and theatres) allowed to } \\
\text { open with precautionary measures and a maximum of } 30 \text { visitors } \\
\text { Secondary schools are partly open; measures taken to prevent contact between students and teachers } \\
\text { within } 1.5 \mathrm{~m}\end{array}$ & $\begin{array}{l}\text { Individuals can schedule a SARS-CoV-2 PCR test if they } \\
\text { have symptoms consistent with COVID-19 }\end{array}$ \\
\hline 24 & Primary schools reopen $100 \%$ (were reopened $50 \%$ since 11 May 2020) & No changes \\
\hline 27 & $\begin{array}{l}\text { Students in secondary schools no longer have to keep } 1.5 \mathrm{~m} \text { distance from each other } \\
\text { Communal sanitation facilities at campsites and holiday parks re-opened } \\
\text { Maximum number of visitors expanded to } 100 \text { people for cinemas, restaurants, cafes and cultural } \\
\text { institutions } \\
\text { Fitness clubs, saunas, wellness centres, club canteens and casinos re-opened }\end{array}$ & No changes \\
\hline 32 & $\begin{array}{l}\text { Hospitality sector opened for reservations (in advance or at the door), with a health check and the } \\
\text { allocation of a fixed seating placement at a table or at the bar (all visitors asked to register to enable } \\
\text { contact tracing) }\end{array}$ & No changes \\
\hline 34 & $\begin{array}{l}\text { Gatherings in private homes limited to six people (residents and guests, aged }>12 \text { years) } \\
\text { Individuals encouraged to work from home as much as possible } \\
\text { Home quarantine reduced from } 14 \text { to } 10 \text { days }\end{array}$ & No changes \\
\hline 39 & $\begin{array}{l}\text { In regions with high incidence of SARS-CoV-2 infections: } \\
\text { Bars and restaurants closed at 1:00 } \\
\text { Maximum group size is } 50 \text { people }\end{array}$ & $\begin{array}{l}\text { Due to shortages in testing capacities, children } \leq 12 \text { years } \\
\text { old with mild COVID-19 symptoms are no longer tested } \\
\text { Essential healthcare and educational personnel can get } \\
\text { tested with priority }\end{array}$ \\
\hline 40 & $\begin{array}{l}\text { Individuals to work from home as much as possible } \\
\text { Gatherings in private homes limited to three guests, excluding children } \leq 12 \text { years old } \\
\text { Maximum group size elsewhere is four people }>12 \text { years old, for instance for reservations in cinemas or } \\
\text { restaurants } \\
\text { The total number of people indoors is limited to } 30 \text { ( }>12 \text { years old), outdoors } 40 \\
\text { Food and beverage outlets closed by } 21: 00, \text { stores closed by } 22: 00 \\
\text { Canteens at sporting facilities closed, no spectators allowed at sporting events } \\
\text { People with a close-contact profession must ask their customers to register } \\
\text { Travel and movements limited as much as possible } \\
\text { All people } \geq 13 \text { years old urgently advised to wear a non-medical face mask in publicly accessible indoor } \\
\text { areas }\end{array}$ & No changes \\
\hline 42 & $\begin{array}{l}\text { Partial lockdown } \\
\text { Gatherings in private homes limited to three guests per day, excluding children } \leq 12 \text { years old } \\
\text { In secondary and higher education, everyone must wear a mask outside of class } \\
\text { All restaurants and bars closed (take-out is allowed) } \\
\text { Public transport only for essential travel } \\
\text { Retail stores closed by } 20: 00 \\
\text { No alcohol sold between } 20: 00 \text { and } 7: 00 \\
\text { Public events cancelled } \\
\text { For everyone } \geq 18 \text { years old, sports only allowed at a distance of } 1.5 \mathrm{~m} \text {; maximum team size is four people } \\
\text { At sporting facilities, canteens, showers and changing rooms are closed } \\
\text { Travel abroad limited as much as possible }\end{array}$ & No changes \\
\hline
\end{tabular}

COVID-19: coronavirus disease; SARS-CoV-2: severe acute respiratory syndrome coronavirus 2.

a Such as runny nose, sneezing, sore throat, cough, fever or sudden loss of smell or taste.

${ }^{\mathrm{b}}$ Exceptions are critically ill children, children who are a confirmed COVID-19 case contact or children who are included in an outbreak investigation.

The following prevention measures have been advised since 12 March and throughout the study period: frequent handwashing, sneeze and cough hygiene, physical distancing of at leas

$1.5 \mathrm{~m}$, self-isolating when experiencing COVID-19-like symptoms or when a household member has a fever and/or shortness of breath, and avoiding crowded places. 
surveillance system, named Infectieradar and modelled on influenzanet [5], was recently implemented to provide more insight into the incidence of COVID-19like symptoms. It may be hypothesised that occupational groups such as HCWs, childcare personnel and educational personnel might be at an increased risk of exposure to other respiratory pathogens with symptoms similar to COVID-19, such as rhinovirus, rendering these professionals more likely to get tested and to test negative for SARS-CoV-2.

Published data on COVID-19-associated deaths $[6,7]$ and hospitalisations [8] by occupation have highlighted HCWs as being at increased risk for severe COVID-19, which is in contrast to our finding of lower test positivity in this group. It is possible that there is selection bias in our data on HCWs, as HCWs employed by a hospital or long-term care facility with direct links to a hospital can be tested via their employer (the hospital laboratory) rather than the PHS test locations. These tests from outside of the PHS are not registered in the CoronIT database and are therefore not included in our analysis. However, some hospital laboratories report the numbers of negative and positive tests directly to RIVM, and separately for patients and employees. In these separate data, the percentages positive among hospital employees are slightly lower than in the tested persons registered in CoronIT as 'HCW in hospital' [9]. The risks of SARS-CoV-2 infection and severity for HCWs do not appear to be higher than average, based on notifications received between June and October (data not shown). Compared with other notified cases aged 17-69 years, we have seen relatively low percentages of hospitalised (0.3\% vs $0.7 \%$ of non-HCW notified cases) and deceased HCWs (0.01\% vs $0.05 \%$ ) since 1 June. For the first wave of COVID-19 in the Netherlands, such comparisons are less informative due to testing policy prioritising HCWs.

\section{Conclusions}

Despite its limitations, the system CoronlT provides the unique possibility of detailed nationwide surveillance of SARS-CoV-2 by population subgroup in the Netherlands. This source of surveillance data will allow evaluation of the COVID-19 epidemic's development in specific subpopulations and occupational groups targeted by prevention measures. We believe these population-level, subgroup-specific surveillance data can also be informative for European countries that do not have data on specific target groups and may inform choices in national policies to slow the spread of COVID-19.

\section{Acknowledgements}

The authors would like to acknowledge the important contributions of all 25 Public Health Services (GGDen), GGDGHOR Nederland and the COVID surveillance team at RIVM.

Funding: This work was funded by the Ministry of Health, Welfare and Sports.
Conflict of interest

None declared.

Authors' contributions

Study design: Susan Hahné, Susan van den Hof, Brechje de Gier and Arianne van Gageldonk-Lafeber. Data collection, management and quality control: Marc Ruijten, Jeroen Alblas, Toos Waegemaekers, Anja Schreijer and Pieter de Boer. Data analysis: Brechje de Gier, Priscila de Oliveira Bressane Lima, Rolina van Gaalen and Pieter de Boer. Manuscript draft: Brechje de Gier. All authors contributed to the final manuscript.

\section{References}

1. $R$ Core Team. $R$ : A language and environment for statistical computing. R Foundation for Statistical Computing. Vienna: R Core Team; 2019. Available from: https://www.R-project.org/

2. Ludvigsson JF. Systematic review of COVID-19 in children shows milder cases and a better prognosis than adults. Acta Paediatr. 2020;109(6):1088-95. https://doi.org/10.1111/ apa.15270 PMID: 32202343

3. European Centre for Disease Prevention and Control (ECDC). COVID-19 in children and the role of school settings in COVID-19 transmission, 6 August 2020. Stockholm: ECDC; 2020. Available from: https:// www.ecdc.europa.eu/en/publications-data/ children-and-school-settings-covid-19-transmission

4. European Centre for Disease Prevention and Control (ECDC). COVID-19 clusters and outbreaks in occupational settings in the EU/EEA and the UK. Stockholm: ECDC; 2020. Available from: https://www.ecdc.europa.eu/en/publications-data/ covid-19-clusters-and-outbreaks-occupational-settingseueea-and-uk

5. Koppeschaar CE, Colizza V, Guerrisi C, Turbelin C, Duggan J, Edmunds WJ, et al. Influenzanet: Citizens Among 10 Countries Collaborating to Monitor Influenza in Europe. JMIR Public Health Surveill. 2017;3(3):e66. https://doi.org/10.2196/publichealth.7429 PMID: 28928112

6. UK Office for National Statistics. Coronavirus (COVID-19) related deaths by occupation, England and Wales: deaths registered between 9 March and 25 May 2020. London: UK Office for National Statistics; 2020. Available from: https://www.ons.gov.uk/peoplepopulationandcommunity/ healthandsocialcare/causesofdeath/bulletins/coronaviruscovid19relateddeathsbyoccupationenglandandwales/ deathsregisteredbetweengmarchand25may 2020

7. UK Office for National Statistics. Coronavirus (COVID-19) related deaths by occupation, before and during lockdown, England and Wales. London:UK Office for National Statistics; 2020. Available from: https://www.ons.gov. $\mathrm{uk} /$ peoplepopulationandcommunity/healthandsocialcare/ causesofdeath/bulletins/coronaviruscovid19relateddeathsbyoccupationbeforeandduringlockdownenglandandwales/ deathsregisteredbetweengmarchand30jun2020

8. Mutambudzi M, Niedzwiedz CL, Macdonald EB, Leyland AH, Mair FS, Anderson J], et al. Occupation and risk of severe COVID-19: prospective cohort study of 120075 UK Biobank participants; medRxiv 2020. Available from: https://www. medrxiv.org/content/10.1101/2020.05.22.20109892V2

9. National Institute for Public Health and the Environment (RIVM). Archief weekrapportages epidemiologische situatie COVID-19 in Nederland. [Weekly update epidemiological situation COVID-19 in the Netherlands]. Bilthoven: RIVM; 2020. Dutch. Available from: https://www.rivm.nl/sites/ default/files/2020-10/COVID-19_WebSite_rapport wekelijks_20201027_1159.pdf

10. National Intensive Care Evaluation (NICE). COVID-19 admissions. Amsterdam: NICE; 2020. Available from: https:// www.stichting-nice.nl/covid-19-op-de-ic.jsp

\section{License, supplementary material and copyright}

This is an open-access article distributed under the terms of the Creative Commons Attribution (CC BY 4.0) Licence. You may share and adapt the material, but must give appropriate 
credit to the source, provide a link to the licence and indicate if changes were made.

Any supplementary material referenced in the article can be found in the online version.

This article is copyright of the authors or their affiliated institutions, 2020. 